\title{
Configurações
}

Revista de sociologia

\section{Uma Mensagem Sensorial. Problematizar horizontes na experiência da comunicação e criatividade em arte e design}

\author{
A Sensory Message. Problematising horizons in the communication experience \\ and creativity in art and design \\ Un message sensoriel. Problématiser des horizons dans l'expérience de la \\ communication et de la créativité dans l'art et le design
}

\section{Eduardo Pedreiro}

\section{OpenEdition}

\section{Journals}

Electronic version

URL: http://journals.openedition.org/configuracoes/6196

DOI: $10.4000 /$ configuracoes. 6196

ISSN: 2182-7419

Publisher

Centro de Investigação em Ciências Sociais

Printed version

Number of pages: 132-146

ISSN: 1646-5075

\section{Electronic reference}

Eduardo Pedreiro, « Uma Mensagem Sensorial. Problematizar horizontes na experiência da

comunicação e criatividade em arte e design », Configurações [Online], 22 | 2018, Online since 21

December 2018, connection on 20 April 2019. URL : http://journals.openedition.org/

configuracoes/6196; DOI : 10.4000/configuracoes.6196 
Pedreiro, Eduardo - Uma Mensagem Sensorial. Problematizar horizontes na experiência da comunicação e criatividade em arte e design. Configurações, vol. 22, 2018, pp. 132-146.

\title{
Uma Mensagem Sensorial. Problematizar horizontes na experiência da comunicação e criatividade em arte e design
}

EDUARDO PEDREIRO*

Faculdade de Belas Artes da Universidade do Porto

\begin{abstract}
Resumo
Este artigo reflete sobre as ligações que temos ao mundo real que têm vindo a sofrer uma alteração profunda com o desenvolvimento das tecnologias da imagem. A visão tem mediado uma forma de existência que nos separa da experiência do real. Começando por refletir sobre a visão e visualidade no presente, considera-se que a experiência sensorial pode ser um caminho para reformular formas de comunicar. $\mathrm{O}$ toque, por exemplo, é o sentido da intimidade, do contacto. É também uma linguagem com leituras racionais e emocionais, que nos permite construir valor ao redor da nossa escala humana. Neste artigo, discute-se a experiência como um processo sensorial mais complexo, bem como a noção de interator (interactor) como sendo expressiva da evolução da sociedade e do observador. A comunicação, entendida como um processo associado a valores estéticos, pode através da criatividade em arte e design constituir-se numa prática sensorial e sinestética? Espera-se, deste modo, contribuir para que estas áreas de reflexão possam definir novos horizontes para estabelecer novos padrões de comunicação, que já estão a ser encarados no domínio criativo.
\end{abstract}

Palavras-chave: complementaridade dos sentidos, interactor, tangibilidade, sinestética, sensory studies.

\footnotetext{
Abstract

A Sensory Message. Problematising horizons in the communication experience and creativity in art and design

This article reflects on the connections we have with the real world, which have undergone a profound change with the development of imaging technologies. Vision has mediated a form of existence that separates us from the experience of what is real. Beginning with a reflection on vision and visuality in the present, it is felt that a sensory experience can be a way to reformulate ways of communicating. Touch, for example, is the sense of intimacy, of contact. It is also a language with rational and emotional readings, which allows us to build value around our human scale. In this article, we 
discuss experience as a more complex sensory process, as well as the notion of interactor as being expressive of the evolution of society and the observer. Can communication, understood as a process associated with aesthetic values, constitute a sensorial and synesthetic practice through creativity in art and design? Therefore, the hope is to help these areas of reflection define new horizons to establish new communication standards, which are already being considered in the creative field.

Keywords: complementarity of the senses, interactor, tangibility, synesthetics, sensory studies.

\section{Résumé}

Un message sensoriel. Problématiser des horizons dans l'expérience de la communication et de la créativité dans l'art et le design

Cet article fait une réflexion sur les connexions que nous avons avec le monde réel, qui ont subi un profond changement avec le développement des technologies de l'image. La vision a véhiculé une forme d'existence qui nous sépare de l'expérience du réel. En commençant par réfléchir sur la vision et la visualité dans le présent, on considère que l'expérience sensorielle peut être un moyen de reformuler les formes de communiquer. Le toucher, par exemple, est le sens de l'intimité, du contact. C'est aussi un langage avec des lectures rationnelles et émotionnelles, ce qui nous permet de créer de la valeur autour de notre échelle humaine. Cet article problématise l'expérience comme un processus sensoriel plus complexe ainsi que la notion d'interacteur comme exprimant l'évolution de la société et de l'observateur. La communication, entendue comme un processus associé à des valeurs esthétiques, peut-elle, par l'intermédiaire de la créativité dans l'art et le design, constituer une pratique sensorielle et synesthétique? Nous espérons ainsi contribuer à ce que ces domaines de réflexion puissent définir de nouveaux horizons pour établir de nouvelles normes de communication, qui sont déjà considérées dans le domaine créatif.

Mots-clés: complémentarité des sens, interacteur, tangibilité, synesthétique, études sensorielles.

\section{Introdução}

A era contemporânea define-se, atualmente, pela tomada de posições paradoxais perante o real. Uma dicotomia entre o ser e o estar instala-se. As nossas perceções são ruidosas, as nossas visões embaciadas, os nossos toques distantes. Nesta era Global, marcada pela revolução tecnológica, a rotina anestesia-nos. Kevin Robins (2003) reflete sobre a importância da ausência na definição dos nossos papéis atualmente enquanto seres sociais, críticos e pensantes que somos; seres altamente visuais num contexto de evolução e inovação tecnológica. A revolução tecnológica redefiniu, tal como defende Robins em O Toque 
do Desconhecido (2003), a nossa posição perante o mundo real. A cultura da imagem, do consumo, a disseminação dos media, aumentaram os nossos níveis de ausência física dos lugares e a capacidade de nos trans e reconfigurar-nos em múltiplos momentos, em diversas circunstâncias e em personalidades variáveis. Somos um “Outro de Qualquer Lugar” (Robins, 2003). Somos nós, e simultaneamente não somos.

Tendo o referido autor identificado que "a verdadeira crise com que se confrontam as sociedades contemporâneas é a crise da ordem social, a crise das relações sociais e das formas de sociabilidade" (Robins, 2003: 29), questiono-me repetidamente acerca das razões pelas quais de cada vez que se abre o potencial de identificação de novas formas de comunicar, a solução ser sempre aquela que já vejo como um lugar-comum: a visualidade. Clarifico desde já que não pretendo afirmar a visão como um sentido negativo ou menos necessário, mas sim compreendê-la como um sentido que determina o nosso posicionamento e define a nossa comunicação no contexto real, na cultura ocidental. Somos dotados de perceções, sete (7) são os sentidos que nos definem, fisiologicamente falando - visão, audição, tato, olfato, gosto, proprioceção e sistema vestibular. O que são eles para nós? Podemos comunicar através deles?

Importa ainda clarificar quem é o sujeito deste artigo. Apropriando-me de alguns conceitos propostos por Caroline A. Jones (2006), refiro-me a essa figura individual, amplamente urbana, industrializada, homo economicus, e utilizadora de tecnologias. Reconhecendo esta figura como recorrente na sociedade atual, bem como relacionando-me individualmente com estes conceitos, o presente artigo encontra-se redigido na primeira pessoa. Enquanto designer de comunicação, artista e ser social, encaro o meio criativo como engrenagem para a geração de novos vocábulos comunicacionais e reflito sobre estas questões, identificando algumas abordagens no campo da criatividade que vejo com interesse na possível definição de uma forma emergente de comunicação e estética.

\section{Visão e Visualidade}

Neste ponto inicial apresento algumas perspetivas sobre a visão e a visualidade como base para o restante desenvolvimento. Considero relevante entendermos, ou relembrarmos, onde se situa a visão (e o sujeito visual, que a pratica e encarna) nos padrões de comunicação contemporâneos pois, para encarar a comunicação num âmbito sensorial, não podemos dissociar quer a visão do campo sensível, quer as permutas relacionais que são feitas entre a visão e os campos cultural e social. 
No já referido ensaio, partindo da cultura da imagem e da revolução tecnológica, Kevin Robins (2003) encara as novas e futuras tecnologias como uma promessa de segurança e proteção, afirmando o humano como um ser possivelmente em vias de ser automatizado em resposta ao seu medo básico de ser sujeito a influências indesejáveis. Este posicionamento assume uma forma de exterioridade perante o real naquilo que considera o ordenamento tecnológico do campo da visão.

A visão tecnologicamente mediada desenvolveu-se como o modo decisivamente moderno de garantir distância relativamente ao que se encontra à nossa volta, de nos retirarmos e insularmos relativamente à assustadora proximidade do mundo do contacto. (...) Para aqueles que têm acesso a elas, as novas tecnologias da imagem estão a facilitar um maior distanciamento e rutura em relação ao mundo. A visão está a ficar separada da experiência, e o mundo está a assumir rapidamente uma qualidade desrealizada. (Robins, 2003; 29).

Deste ponto de vista, as nossas ligações com o mundo real alteraram-se na era moderna e com a emergência tecnológica. De acordo com Robins (2003), assim como segundo Jones (2006), a modernidade definiu um modo hierarquizado de experienciar o contexto real. A visão figura como o sentido privilegiado e determinador da compreensão e experiência do mundo. Segundo os autores, esta experiência racionalizou-se na era moderna, herança derradeira do tempo presente. Esta hierarquização da experiência dos sentidos e o domínio da visão também são realçadas por Ellen Lupton (2018), que também considera a visão - a observação - como estando na fundação do conhecimento contemporâneo. Esta autora refere ainda as tecnologias digitais que, ao canalizarem fluxos de informação e imagem, alienam crescentemente o sujeito de uma perceção sensorial do mundo. Tais reflexões encontram pontos de contacto com a noção de exterioridade de Robins (2003). A possibilidade do sujeito se tornar exterior à experiência permitiu-lhe reconfigurar-se sob formas e em contextos nunca antes pensados, que inevitavelmente alteraram a sua forma de percecionar e sentir o mundo, alterando a natureza da própria vida humana. Uma extensão virtual do ser é cada vez mais imposta e absorvida, e estabelece-se o que eu denominei inicialmente por uma vivência dicotómica entre ser e estar.

A visualidade, enquanto produto da visão, é construída em resposta aos contextos culturais, tecnológicos e sociais, não podendo deixar de referir as tecnologias sociais que mediam atualmente e em grande parte os nossos comportamentos íntimos e em sociedade. No entanto, W.J.T. Mitchell, no seu ensaio "Showing seeing: a critique to visual culture" (2002), defende que a visão deve ser problematizada como um produto social, mas não sem simultaneamente recontarmos a história da sociabilidade enquanto produto da visão (Mitchell, 2002; 171). A era contemporânea é marcada pelas duas óticas, que são indissociáveis na medida em que já nada acontece unilateralmente nestes domínios - a exterioridade constrói a visualidade, no entanto a visão não 
cessa de construir o distanciamento. Mitchell (2002) define, parcialmente, a Cultura Visual como sendo um campo que não deve pensar a hegemonia do visual enquanto consequência das tecnologias ou dos media, nem como sendo uma noção que se enquadre no panorama atual. Aponta que, para o pensamento da Cultura Visual, a visão deve ser problematizada de acordo com a sua relação com os demais sentidos pois estes também devem ser entendidos enquanto construtores de práticas culturais (Mitchell, 2002; 174). Estando a tecnologia e a experiência tão intimamente ligadas, tal como defende Robins (2003), definindo tão fortemente os padrões comportamentais e os fenómenos comunicacionais de hoje, como localizar esta relação sensorial que Mitchell deixa sobre o véu?

\section{Proximidade e Tangibilidade}

\subsection{Redefinir o Tangível}

Ao refletir acerca da pista sensorial deixada por Mitchell (2002), podemos indagar acerca do valor e das construções culturais associadas aos restantes sentidos. Tendo em consideração as ilações de Robins (2003), a visão figura como um sentido que contribui ativamente para definir uma experiência de exterioridade perante o mundo físico. Assim sendo, torna-se necessário recentrar a relação entre os sentidos de modo a evidenciar a complexidade que lhes é intrínseca. Coloco então a possibilidade de integrar a noção de tangível numa possível forma de experiência sensorialmente mais complexa do que uma experiência de exterioridade Quando falo de tangibilidade surge, de imediato, o conceito de automatização, na medida em que, frequentemente, nas nossas vivências reais estamos mais autoprogramados para evitar do que para questionar ou interagir. Somos dotados de características extravirtuais que poderiam ser pensadas como menores, na medida em que são o que nos caracteriza enquanto seres orgânicos. Nesta reflexão e no trabalho que procuro desenvolver, as características extravirtuais são perspetivadas no seu potencial de renovação da qualidade da experiência criativa em arte e design, áreas que se ancoram fortemente numa cultura tecnológica e visual. Do meu ponto de vista, esta renovação passa por interpretar a tangibilidade como conceito para comunicar, com potencialidades e problemáticas a serem desenvolvidas. Importa então perguntar: onde se situa o tangível? No oposto da exterioridade da visão, vejo o tato. Robins (2003), no seu ensaio, traz o tato ao encontro da visão enquanto práticas e valores culturais que ao representarem o "desejo de desincorporação e o afastamento em relação à experiência” (Robins, 2003; 47) ainda marcam a sociedade contemporânea.

Irei então considerar o tato, a aceitação da existência incorporada, e a possibilidade de experiência (ou seja, a possibilidade de ser tocado pelo 
desconhecido). O que está em causa é o modo como a experiência sensorial - e consequentemente cultural e intelectual - moderna se tornou poderosamente associada à visão (o sentido da dissociação), enquanto ao mesmo tempo o significado do tato (o sentido íntimo) tem sido reprimido e desvalorizado. (...) O problema fundamental está na divisão e separação da experiência sensível na cultura moderna - é isto que torna tal polarização possível. (Robins, 2003; 47).

Tal polarização é salientada por Robins (2003). No entanto, do meu ponto de vista, a experiência sensorial pode ser uma chave para se ver além desta questão. Fica subjacente às considerações do autor que os sentidos deveriam atuar em complementaridade ao invés de operarem especificamente ou direcionados a atividades em concreto, ainda que, logicamente, exista uma comunicação in ou subconsciente entre as diversas perceções. Esta ideia de complementaridade dos sentidos é levantada mais claramente por Juhani Pallasmaa ao refletir a prática da arquitetura na sua obra "The Eyes of the Skin - Architecture and Senses" (2005).

O tato é o sentido que estabelece as pontes, não há toque sem se ser tocado. Sendo um sentido de experiência e de proximidade, este é um dos sentidos do medo, da vulnerabilidade, da exposição, tal como diz Robins (2003). Há, no entanto, um outro lado - o toque enquanto linguagem. Isto é, enquanto linguagem moral, emocional e visualmente abstrata para a sensação e valorização daquilo que podemos transmitir uns aos outros. Ao sermos capazes de redefinir o tangível, e de nos redefinirmos enquanto tangíveis, estamos impreterivelmente a abrir possibilidades de comunicação. Entendendo a experiência como uma noção sensorial, este processo de redefinição deve ter em consideração os diversos sentidos, integrando horizontes de solução mais amplos comparativamente a uma experiência de exterioridade.

\subsection{Um Oitavo Sentido}

Juhani Pallasmaa (2005), na já referida obra, aponta para a existência de transferências subtis entre as experiências tácteis e gustativas, naquilo que é a vivência de um espaço arquitetónico, defendendo que a própria visão do espaço é reconfigurada por perceções do palato em resposta à cor e textura dos materiais e dos lugares. O sentido gustativo é referido, na medida em que pode ser entendido como o mais básico e primário de todos os sentidos, visto ser exercido de forma prática em resposta a uma necessidade natural - a alimentação. Sendo a boca o princípio do conceito de espaço e este o mais primário dos sentidos, é também a partir deste que se baseia a experiência percetiva. Segundo o autor, o gosto atua aqui como uma componente da experiência espacial que se relaciona concreta e, para muitos, secretamente com o objeto e com o contexto e, arrisco-me a dizer (recordemos o nosso leque de sete sentidos, entre os quais se 
encontra a proprioceção), com a própria noção propriocetiva. Esta observação é apoiada por uma visão acerca da materialidade e do tempo enquanto definidores da vivência sensorial do espaço. Estando o domínio percetivo ligado aos elementos espaciais, para o autor a noção de materialidade está intimamente ligada à forma como sentimos o espaço, que pode passar pelas transações entre o tato, o gosto e a visão. No entanto, esta noção encontra-se hoje enfraquecida, resultando na produção de espaços estéreis para a esfera sensível, o que tem impacto na vivência temporal do espaço. Refere, assim, a insensibilidade material na criação arquitetónica contemporânea, solidificada com materiais visivelmente opacos (naquilo que o olhar pode canalizar para as restantes perceções), desprovidos de entendimento do domínio sensível e das possibilidades que a vivência do espaço pode oferecer. Menciona, por isso, o uso em grande (e desmedida) escala de materiais de construção como o vidro, o metal e o plástico e reflete acerca da experiência temporal enquanto consequência da frieza material:

o enfraquecimento da experiência do tempo nos ambientes de hoje tem efeitos mentais devastadores (...) Temos todos uma necessidade de nos agarrarmos ao facto de que estamos presos à continuidade do tempo (...) A arquitetura domestica a infinidade do espaço e permite-nos habitá-lo, mas também deveria domesticar a infinidade do tempo e permitir que habitemos a sua continuidade. (Pallasmaa, 2005; 32).

Tal linha de pensamento leva-me a questionar acerca do limite do trabalho sensorial naquilo que pode ser a fronteira entre o domínio fisiológico e o domínio psicológico da perceção. A perceção do tempo e o trabalho da sensação do tempo passam, assim, a figurar como vertentes percetivas que a abordagem sensorial pode explorar através de um trabalho individual ou coletivo com diferentes públicos. Lanço a questão a mim próprio se poderei falar da perceção do tempo como um oitavo sentido, na medida em que o tempo apresenta-se a nós de forma objetiva e subjetiva, cronológica e psicologicamente, tal como é abordado na teoria da literatura, em autores como Vítor Manuel de Aguiar e Silva (2007). Surge então, aqui, a perceção do tempo por parte do indivíduo, que se ajusta e posiciona perante essa perceção. Assim, surge a noção de posicionamento e, consequentemente, de tangibilidade do tempo. Este conceito parece-me de relevância na medida em que a nossa memória, enquanto produto e interpretação do tempo, é construção também sensorial, passível de se ir reconfigurando ao longo da vida de acordo com o nosso posicionamento (distância ou proximidade) perante as nossas memórias. Tendo nós a capacidade de potenciar ou reconfigurar o significado do tempo, estamos também a trazer camadas de complexidade à experiência, integrando os sentidos de um modo mais alargado. 


\subsection{A importância da experiência}

Tendo abordado a perceção do tempo e da memória como componentes relevantes para a experiência sensorial. Refiro agora o estudo realizado por Kelvin E. Y. Low que, enquadrado nas áreas da sociologia e da etnografia, investiga as ligações entre o sentido do olfato e a memória. O olfato, no artigo "Olfactive frames of remembering: theorizing self, senses and society" $(2013)^{1}$, é estudado de acordo com os seus significados culturais e sociais, bem como na sua relação com a memória. Este sentido é apontado como uma bússola nos julgamentos morais que efetuamos, tendo nós já construído, no curso da nossa existência, conceitos de identidade olfativa que colocamos em prática de forma inconsciente (Low, 2013). As noções de transgressão olfativa, tais como odor corporal, flatulência ou falta de cuidados de higiene, surgem na construção de associações entre o cheiro, a identidade e a sociabilidade, sendo a identidade olfativa um fator de mediação da proximidade em contexto social (Low, 2013). Segundo Low (2013), construir uma identidade olfativa socialmente aceite é uma reprogramação dos atos de aproximar, evitar, discriminar ou construir valor subjetivo ao redor de algo ou de alguém. Este é um exemplo de como o odor pode ter uma relação tão próxima com a memória e de como juntos definem o posicionamento do sujeito e do que ele define como tangível.

De acordo com Caroline A. Jones (2006), o olfato afigura-se como um sentido pouco problematizado do ponto de vista conceptual no campo da arte. Esta ideia também é reiterada e desenvolvida na área do design por Ellen Lupton (2018), bem como por Adam Jasper e Nadia Wagner (2018). Tendo em consideração a segmentação da experiência sensorial definida na era moderna, o sentido do olfato apresenta-se como um sentido que foi distanciado do debate teórico, dada a sua resistência em ser codificado e apreendido de acordo com os padrões de conhecimento delineados pela visão moderna. Este facto, limitou o seu entendimento de um ponto de vista verbal, bem como fez com que o sentido olfativo viesse a constituir uma barreira de argumentação, evitada ou contornada em campos como a arte, o design e a estética. O olfato representa um sentido oportuno de trabalhar pois, segundo Jones (2006), este atinge o observador mesmo quando ele não observa, sendo mais veloz do que a sua atenção e a sua consciência, convocando vivazmente a memória e a emoção (Jones, 2006, pp. 13-14)2. Dadas as considerações de Low (2013), este sentido também tem uma forte capacidade de nos transportar para onde não olhamos e também para onde não estamos. Ao estar profundamente associado à

1 Este estudo baseia-se em testemunhos de 71 pessoas entre 20 e 45 anos de idade.

2 None other [sense] communicates so immediately and directly to the sites of memory in the brain, bypassing conscious recognition to summon core emotional states associated with the minute chemical combinations that first stimulated that neuron for that specific scent. (...) Smell - no doubt because of our modern resistance to its cues - is thought to get us when we're "not looking", to take us unawares and bypass conscious will". 
memória e sendo mais veloz do que o pensamento consciente, o olfato é ainda um exemplo de uma perceção que se desvia de uma compreensão e descrição estritamente verbal. Deste modo, a perceção olfativa pode ser apropriada como objeto de trabalho de modo a mergulhar nos domínios intangíveis e subjetivos da experiência sensorial, conferindo-lhe complexidade e integridade.

No trabalho com o sentido do olfato, Low (2013) explora a memória olfativa e a sua relação com a identidade do indivíduo e as circunstâncias relembradas. O olfato é utilizado pelo autor como forma de ativar a recordação de momentos da infância ou reflexões sobre relações humanas. Este sentido é então associado não apenas ao tempo cronológico do momento passado, mas também ao tempo psicológico e à emotividade envolvidos, quer no momento da experiência, quer no momento presente em que é relembrada. Um exercício simples realizado por Low com uma das participantes do seu trabalho, passa pela lembrança da sua avó partindo da memória olfativa. Este exercício abriu-lhe a possibilidade de reexperienciar um momento passado por despoletar a reconstituição precisa de objetos e do contexto. Esta reconstrução é uma chave para a caracterização mental do local e acontecimento passados, trazendo-os para o presente (Low, 2013). O cheiro pode, por isso, constituir uma espécie de "gatilho da memória", mas também um fator determinante no comportamento, na comunicação e na avaliação das experiências por ele mediadas.

Uma vez que já falamos de tangibilidade e proximidade, associando-as também à perceção do tempo, bem como à memória, julgo ser pertinente referir a componente participativa nos processos da experiência sensorial, na medida em que é através desta componente que se estabelecem as pontes entre o objeto, o fenómeno e o sujeito, tendo em consideração as estratégias de trabalho que, atualmente, abrangem cada um dos sentidos. A noção de participação já vem sendo pensada no campo da arte, nomeadamente na ótica da instalação, como considera Nicolas de Oliveira no livro Installation art in the new millenium: the empire of the senses (2003). O autor faz referência ao conceito de "estética relacional" de Nicolas Bourriaud que visa a conceção do objecto artístico centrada na relação que pode construir com o sujeito ou público, promovendo o convívio, a interação e a relação na geração de um processo também comunicativo. Oliveira diz, então, que "nos anos 70 e 80, vivíamos numa sociedade de espetáculo, nos anos 90 numa sociedade de participantes, e agora estamos a desenvolver uma sociedade de interactors", acrescentando que "é necessário explorar a asserção de que o espectador, o observador de uma obra de arte, é agora um "interactor" e os contornos em que isto afeta o artista e os meios por ele escolhidos para se dirigir ao público.” (Oliveira, 2003; 106).

Um dos artistas que revejo na base da problematização da participação no espaço artístico, e que me parece uma referência para a compreensão do conceito de interator (interactor) é, por exemplo, o brasileiro Hélio Oiticica. $\mathrm{O}$ trabalho deste artista transporta a componente experimental e participativa 
para a vivência da obra de arte, abrindo portas às dimensões geradas pela participação, que escala para a interação, por exemplo com a afirmação da componente performativa. Exemplos de obras como "Cosmococa - Programa in Progress" (com Neville D’Almeida, 1973), ou "Parangolé” (pela primeira vez em 1965), parecem-me exemplos claros que problematizaram e continuam a caracterizar a expansão (ou mutação) do papel do observador e o posicionamento do sujeito perante a obra enquanto objeto, espaço ou fenómeno, e a sua vivência. Num passado mais recente, identifico a obra "Storm Room" (2009) de Janet Cardiff e George Bures Miller como incorporação destes conceitos. Nesta obra, o público é convidado a entrar e permanecer sentado numa sala como uma encenação de uma tempestade - chove torrencialmente no exterior; cai água do teto; o ambiente é pouco iluminado, pontuado pelo faiscar elétrico das lâmpadas; o som da tempestade preenche o espaço. O observador transfigura-se a partir do momento em que entra na sala, ao estar imerso numa experiência sensorial que o absorve naquele espaço, havendo um impacto do espaço sobre o sujeito, que é agora um interator (interactor). Assim, o indivíduo é convidado a sentar-se e integrar o momento proporcionado pela obra, com todas as sensações mais ou menos desconfortáveis que podem ser geradas, amplificando a experiência do espaço e do tempo.

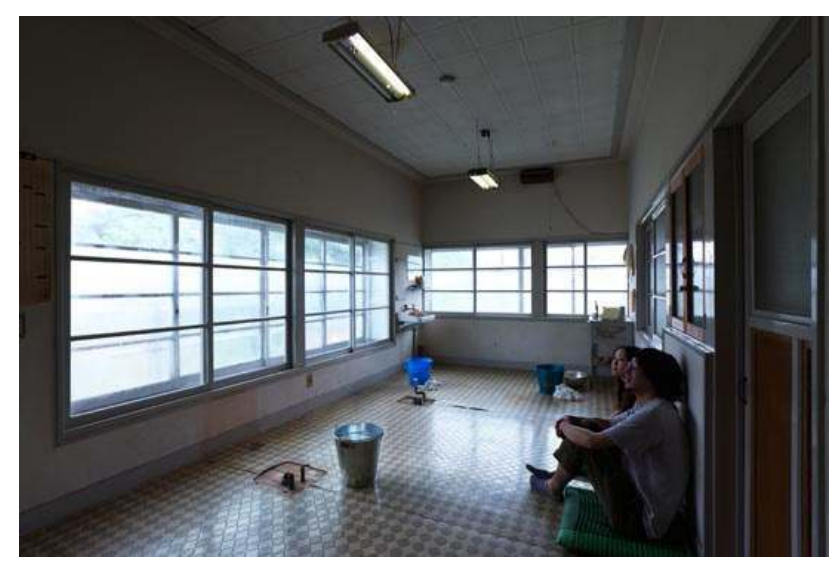

Fig.1 - “Storm Room”, Cardiff \& Miller, instalação, 2009

Estas observações podem parecer contraditórias dadas as reflexões que foram feitas no início deste artigo acerca da visão e da visualidade. Todavia, e clarificando, foco estes últimos pensamentos naquilo que é a renovação do observador no espaço da exposição ou do museu. Esta conversão do observador em interator (interactor), agora além do espaço artístico, é algo que já se tem vindo a prenunciar, por exemplo, com o aparecimento do touch screen 
em que o toque media, em primeira instância, a experiência visual e auditiva que temos. Porém o observador, apesar de interagir, ainda está a exercer uma experiência de exterioridade, não havendo uma redefinição da proximidade do sujeito perante o objeto, espaço e tempo que observa e controla. O ecrã é o limite máximo da sua interação enquanto observador e prevalece a ideia de o “Outro de Qualquer Lugar” de (Robins: 2003), ao invés do conceito de interator (interactor) enquanto elemento envolvido no contexto, como sugerido por Oliveira (2003).

\section{Pontos de chegada}

Esta forma de conceber a experiência - entendendo os sentidos de um modo mais alargado e o público-interator (interactor) - oferece possibilidades que, a meu ver, se podem expandir ao campo da comunicação, na renovação da linguagem quer dos meios quer dos intervenientes (ainda não encontrei termo melhor). Os processos de renovação, como já foi mencionado, não são processos novos na sociedade ocidental. Indo um pouco mais atrás no tempo, dou o exemplo da modernização do observador que se verificou com a emergência das tecnologias da imagem desde o início do século XX, processo que ativamente definiu as linguagens dos observadores e dos meios visuais contemporâneos. Focando a experiência sensorial em arte e design, identifico duas áreas de atuação que se complementam e me parecem importantes: o desenho do sentido e a associação entre sentidos e sensações. Passo a clarificar. Identifico, em trabalhos de artistas e designers, formas de trabalho sensorial que partem de uma aproximação objetiva aos sentidos e às suas possibilidades de comunicação. Por outro lado, a abordagem sensorial também se pode desenvolver refletindo de que forma é que o estímulo de um sentido pode trocar informações com outros sentidos, com a razão e as emoções, e produzir perceções novas, sendo isto o que refiro neste momento com o termo sensação. Por sua vez, estas duas áreas de atuação, ao poderem estar articuladas, parecem-me importantes para a caracterização de uma comunicação sensorial.

$\mathrm{Na}$ ótica do desenho do sentido, vejo por exemplo a artista Sissel Tolaas, e a sua fragrância "Dirty 1" da obra It must be the weather, part 1: Dirty 1 (2001). Nesta obra, a artista instala, em espaço museal, uma máquina capaz de detetar e sintetizar os odores que circulam naquele lugar, para assim fabricar um perfume que reúna as características olfativas do espaço. Este projeto artístico parte da materialização concreta da sensação olfativa na captura de um espaço, como se pudesse estabelecer uma analogia entre a captura fotográfica e a fragrância criada, em que neste caso a captura assume a forma de odor.

Já a segunda área de atuação, a associação entre sentidos e sensações, é desenvolvida em trabalhos de Oiticica, como é o caso de “Tropicália” (1967). 
Nesta instalação, Oiticica sugere aos visitantes que entrem no espaço da instalação, desafiando as suas expectativas perante um objeto museal. A instalação caracteriza-se como um cenário de solo arenoso e plantas, com dois "Penetráveis" nesse espaço: o "PN2 ‘A Pureza é um Mito”" (1966-67) e o "PN3 "Imagético”" (1966-67). Oiticica propõe ao público que envolva o corpo na experiência do objeto artístico, apelando a um envolvimento dos sentidos. No caso do "PN3 'Imagético"” (1966-67), além do “Penetrável”, isto é, de estar inserido no cenário descrito pela instalação "Tropicália” (1967), este compõe um espaço que agrega estímulos aos diversos sentidos. O "Penetrável” convida o sujeito a entrar num percurso delimitado por paredes de tecidos e pelo solo arenoso; pontuado por cheiro como é o caso da essência de patchouli; terminando num espaço privado de luz, com a exceção de um televisor que coloca o estímulo visual como elemento central. O momento vivenciado nesta obra, além do estímulo material e tátil, integra estímulos de ordem química (o cheiro) e luminosa (a escuridão e a imagem), que são integrados num espaço desenhado para ser ocupado pelo corpo humano. Focando os estímulos aos diversos sentidos, este momento propõe uma experiência sensorial complexa que define o modo como o público descobre o objeto que habita. Em última análise, é esta noção de complementaridade entre sentidos que transmite a integridade e preserva o caráter autêntico da experiência.

Estando o sentido e sensação presentes no momento da comunicação, e sendo a associação entre sentidos e sensações uma componente que envolve a troca de informações entre os sentidos, a razão e a emoção, produzindo novas perceções, ocorre-me uma figura de estilo da literatura, a sinestesia. Literariamente, a sinestesia verifica-se com a presença de referências sensoriais diferentes na mesma frase, porém tal conceito não se fica por uma questão literária. Partindo da observação das perceções, a sinestesia constitui ainda uma característica neurológica. O sinesteta é aquele que perceciona o mundo de uma forma diferente daquela da maioria de nós, com os sentidos não apenas a operarem em cada um dos seus domínios, mas numa troca de informações e associações que altera a natureza do real e da vida comparativamente com as nossas noções destes. Atribuir sentimentos a cores, visualizar cores ou formas ao ouvir música, saborear toques, etc. são formas de fazer ocorrer esta transferência sensorial, construindo uma sensação a que poucos de nós têm acesso. De forma sumária, sinestesia, etimologicamente, deriva do grego; synaísthesis, syn significa junto, simultaneamente; aísthesis significa sensação, perceção, palavra que se encontra também nas origens do termo estética, que deriva do adjetivo grego aisthéticos - que tem a faculdade de sentir ou ser compreendido pelos sentidos. Ao refletir acerca da perceção sinestésica, não apenas na literatura, mas também como característica neurológica, poderemos falar de uma sinestética, isto é, a estética refletindo valências da sinestesia. Estamos então a 
falar da sinestética enquanto um novo campo de reflexão acerca da mensagem sensorial como meio para renovar padrões de comunicação.

De acordo com a minha forma de entender as questões que tenho vindo a abordar, a prática sinestética pode ser uma plataforma de desenvolvimento do trabalho sensorial. Um exemplo de trabalho sinestético pode ser o desenvolvido pelo artista Niel Harbisson em 2004: um aparelho que lhe permite detetar a cor através da sua sonorização, ou seja, através de uma conversão das diferentes frequências de luz em frequências auditivas captáveis pelo ouvido. Estamos a falar de uma conversão de informação entre dois estímulos sensoriais distintos na produção de uma mensagem nova para o horizonte da perceção: em vez de vermos cores, também ouvimos cores.

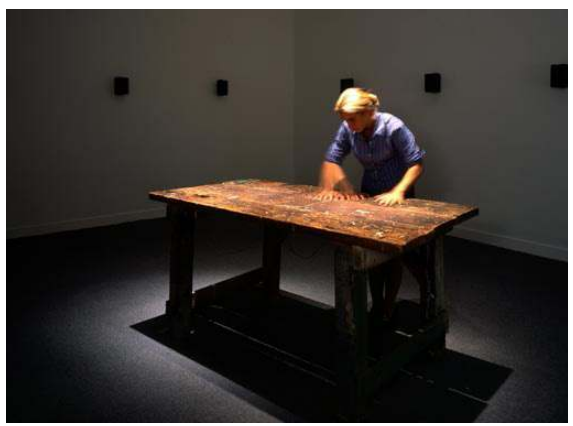

Fig.2 - “To Touch”, Janet Cardiff, instalação, 1993.

Os conceitos de proximidade e tangibilidade já enunciados, e as noções de complementaridade dos sentidos e de interator (interactor), associados ao que pode ser uma sinestética, facultam-nos algumas ferramentas para começarmos a explorar uma renovação no âmbito da comunicação e da criatividade.”. Nesta ótica de entendimento do trabalho sensorial, refiro a obra "To Touch" (1993), da artista Janet Cardiff.

O interator (interactor) é convidado a dirigir-se a uma mesa e a tocar-lhe. A resposta, gerada pela mesa, provém do espaço numa experiência imersiva com a utilização do som, tendo cada toque uma tradução sonora diferente de acordo com o ponto em que a mesa é tocada. Esta obra permite-nos também pensar na experiência do tempo por parte do sujeito e de como a participação contribui para a construção da experiência e de significados na esfera dos sentidos. Ainda na mesma artista, agora juntamente com George Bures Miller, e observando os mesmos aspetos, dou o exemplo do "Cabinet of Curiousness" (2010). Nesta obra, o público interage com um armário de gavetas, que emite som de acordo com a gaveta aberta pelo indivíduo. Aqui, a ação e o toque conduzem a uma interação entre o sujeito e o objeto que, por sua vez, responde 
com som à ação efetuada pelo interator (interactor). A obra vai por isso além do objeto, havendo um posicionamento do sujeito também relativamente ao tempo. Chamado a interagir, o sujeito depara-se com um abrandamento que pode dedicar a conhecer o objeto, tempo esse que contribui para a valorização da experiência. A visão, nestes exemplos, funciona, tal como os restantes sentidos, como um sentido de complementaridade e não como um sentido que determina totalmente o envolvimento do indivíduo.

A noção de mensagem sensorial, ancorada numa experiência com camadas de significado e complexidade que procuram o envolvimento com o sujeito, pode integrar os aspetos debatidos neste artigo. Deste modo, torna-se possível formular diferentes aproximações aos domínios criativo e da comunicação. A subjetividade da experiência apresenta-se como uma matéria de reflexão implícita neste tema de trabalho, contudo, o que me parece de maior relevo são as potencialidades na geração, transmissão e retenção de significados. O efeito sobre a memória e o entendimento do público são fatores determinantes para o sucesso da mensagem sensorial, cuja vertente cognitiva não deve ser esquecida, sendo a cognição um tema a ser debatido por mim noutra ocasião. As considerações elencadas no decorrer deste artigo são tecidas como matéria de reflexão e de prática projetual em arte e design, importantes para uma comunicação mais próxima e mais forte, que transponha os domínios visuais e virtuais e valorize a dimensão social e participativa dos intervenientes.

\section{Referências bibliográficas}

ELUARD, Max (2011), Hélio Oiticica - Museu é o Mundo, disponível em: https://www.youtube. com/watch?v=FipU4XoPAsI [consultado em: 17 de Fevereiro de 2017].

HARBISSON, Neil (2012), I listen to color, disponível em: http://www.ted.com/talks/neil_ harbisson_i_listen_to_color [consultado em: 28 de Fevereiro de 2017]

JONES, Caroline A. (2006), "The Mediated Sensorium", in Caroline A. Jones, Sensorium: Embodied Experience, Technology, and Contemporary Art, Cambridge, Massachusetts, MIT Press, 1-49

LAVERTY, Aidan (2008), When Senses Collide, disponível em: http://www.dailymotion.com/ video/x2naeka [consultado em: 31 de Janeiro de 2017].

LOW, Kelvin E. Y. (2013), “Olfactive frames of remembering: theorizing self, senses and society”. Sociological Review, 61(4), 688-708 [Online], disponível em: https://doi.org/10.1111/1467-954X.12078 [consultado em: 14 de Dezembro de 2016].

LUPTON, Ellen \& LIPPS, Andrea (2018), "Why Sensory Design?”, in Ellen Lupton \& Andrea Lipps, The Senses: Design Beyond Vision, Nova Iorque, Cooper Hewit, Smithsonian Design Museum \& Princeton Architectural Press, 9-36

MACHADO, José Pedro (1977), Dicionário Etimológico da Lingua Portuguesa (3.a ed., Vol. 2, 5), Livros Horizonte.

MITCHELL, W. J. T. (2002). "Showing seeing: a critique of visual culture”, Journal of Visual Culture, 1, 165-181. 
OLIVEIRA, Nicolas, OXLEY, Nicola \& PETRY, Michael (2003), Instalation art in the new millenium: the empire of the senses, Londres: Thames \& Hudson.

PALLASMAA, Juhani (2005), The Eyes of the Skin: architecture and the senses, Great Britain: Wiley-Academy.

ROBINS, Kevin [1996] (2003), “O Toque do Desconhecido”, Revista de Comunicação e Linguagens, Imagem e Vida(31), 27-57. 